\title{
DAKWAH DALAM TRADISI AKADEMIK DAN STUDI ISLAM
}

\section{Eko Nopriyansa}

STAI Bumi Silampari Lubuklinggau Indonesia ekonopriyansyah@gmail.com

\begin{tabular}{ll}
\hline & Abstrak \\
\hline Article History & The success of the leaders of the \\
Received: 20 April 2020 & spread of Islam in the past, has made \\
Revised: 03 Mei 2020 & Indonesia as the largest Muslim \\
Accepted: 04 Mei 2020 & population in the world without \\
\hline Keywords: & leaving a historical trail of warfare \\
Da'wah, Academic & and violence, so that in its \\
Traditions,Islamic Studies & development, Indonesia's strategic \\
& role in tackling various social and \\
& humanitarian problems, has \\
& displayed a face of wisdom and \\
& sought to show to the world of their \\
& maturity in exposing the plurality and \\
& diversity of the population, which is \\
& within the territory of the Unitary \\
& Republic of Indonesia. Furthermore, \\
& no less interesting, even though \\
Indonesia is dominated by Muslims \\
as a majority, Indonesia is not a \\
country that claims a religion, but the \\
Indonesian people recognize their \\
identity as the Pancasilalis people. In \\
this research is an effort to see \\
globally the application of da'wah in \\
Cross-Asia both regarding Models, \\
Implementation, Theory, to various \\
academic phenomena of Islamic \\
Leaders across Asia in exposing \\
Da'wah as a discipline of Science or \\
as a belief in totality in Islam, so that \\
really can find various patterns and \\
social relevance about how the \\
implementation of Da'wah in various \\
\hline
\end{tabular}




regions, both as an academic
discipline, as well as subjective
beliefs. So that in the end, it can
encourage practitioners and
propaganda activists to synchronize
the implementation of their da'wah
with the science methodology, so that
the Da'wah process without reaping
significant obstacles in the midst of a
social society that is Plural and full
of diversity.,

\section{Pendahuluan}

Akademik dengan segala tradisinya, telah menunjukan bahwah ia memiliki andil yang besar dalam perkembangan dan pengembangan Ilmu Dakwah, terutama sebagai Transformasi ilmu yang akan membantu praktisi dakwah atau pemerintah dalam mengatasi masalah-masalah sosial dan keagamaan yang sedang dihadapi ditengah-tengah masyarakat. Lebih jauh, dalam sosiologi pengetahuan, kaum Intlektual dimasukkan sebagai kelas sosial baru sebagai kelompok yang menguasai ilmu pengatahuan dan dengan pengetahuannya ini, nampaknya posisi masyarakat Intlektual mendapat perhatian sendiri bagi masyarakat luas, karna dengan pengatahuannya diyakini bisa menyampaikan pandangan yang objektif dan netral dalam memberikan pandangan terhadap suatu masalah sosial. Oleh karna itu, Intlektual memiliki ciri khas dengan kemampuannya untuk meng-Edukasi dan menjawab masalah masalah sosial secara kritis, baik melalui pembicaraan ataupun melalui tulisan dalam lingkup public untuk diketahui oleh masyarakat luas.

Tulisan ini, berupaya menjelaskan bagaimana Dakwah mentransformasi diri menjadi suatu disiplin Ilmu secara garis besar, serta menampilkan berbagai problema dalam implementasi dakwah di berbagai kawasan masyarakat muslim di asia, tradisi akademik yang menjadi analisis dalam studi dakwah yang dilakukan oleh berbagai kalangan dalam tulisan ini, menjadi bahan evaluasi penting utuk mengimplementasikan dakwah kepada masyarakat luas, terutama bagi praktisi maupun mahasiswa yang tengah menggeluti studi-studi dakwah. 


\section{Metode Penelitian}

Penelitian ini adalah penelitian Kualitatif dalam bentuk studi kepustakaan.Data dalam penelitian ini didapat dari berbagai sumbersumber tertulis seperti buku, artikel ilmiah, Koran, majalah, pamlet dan sejenisnya. Pengumpulan data dalam penelitian ini dilakukan dengancara merangkum, mengorganisasikan dan merumuskan pendapat-pendapat berbagai para ahli yang tertuang dalam dokumen tertulis sepert buku, jurnal, artikel, Ebook dan sejenisnya." (Abuddin Nata, 2006: 387).

\section{Pembahasan}

\section{Dakwah dan Ilmu Pengatahuan}

Dalam perkembangannya, dakwah bukan saja menjadi simbol danprofesi yang dilakukan oleh praktisi Agama dalam pengertian sempit namun dakwah menjadi suatu disiplin ilmu yang memiliki kontribusi sosial dalam menanamkan nilai-nilai luhur kedalam tatanan masyarakat, aktivitas sosial dalam penerapan Dakwah ditengah-tengah beragamnya corak dan latar belakang masyarakat, menuntut para pendakwah untuk benar-benar memiliki kecakapan dalam memahami Ilmu sosial.Barang kali hal inilah yang memperkuat keyakinan Abdul Munir bahwah "kecenderungan kehidupan modern yang paling menarik adalah hubungan dakwah dengan kemajuan Iptek." (Abdul Munir, 1993: 164) Lebih jauh, Profesor Abdul Aziz dalam salah satu artikel ilmiah yang di muat di Universiti Malaya meyakini bahwah dakwah merupakan suatu langkah yang dapat mengembangkan potensi yang dimiliki manusiaselain sebagai upaya dalam meningkatkan spiritual keagamaan :

Ajaran wahyu tidak akan sampai kepada masyarakat untuk dikenali dan diikuti kecuali melalui dakwah yang diusahakan dengan pelbagai cara dan bentuk. Hal ini supaya manusia berfungsi dengan baik dan potensinya perlu dibangunkan atau dipulihkan apabila mengalami kerosakan mengikut caranya yang sesuai. Dakwah memainkan peranannya dalam usaha pembangunan dan pemulihan dengan pelbagai cara dan bentukmengikut panduan Ilahi. Dakwah membawa ke arah pencapaian matlamat manusia dihidupkan di dunia ini. Maka, dakwah sangat diperlukan.(Abdul Aziz, 2013: iii) 
Senada dengan itu, jika kita menganalisa subtansi dakwah dengan histori penyebaran Islam pada masa kehidupan Nabi Muhammad kala itu, maka kita dapat memahami bahwah penyebaran Islam melalui persentuhan sosial dengan semangat kemaslatan seluruh umat manusia, penuh toleransi, namun tanpa sedikitpun mengurangi prinsip-prinsip kesucian dan kemurnian dakwah. Beberapa para ahlih seperti Syaikh Syafiyurrahman, Muhammad Said Ramadhan, hingga Ahmad Al-ushairy, senantiasa menyajikan secara Representatif dengan mengurai "pendekatan dakwah dengan upaya memahami eksistensi sejarah" penyebaran Islam.(Syaikh Syaifurrahman,1997: xvii-xxxiii). Oleh karna itu, bukan tanpa alasan, jika Bustanudin Agus dalam bukunya Agama dalam Kehidupan Manusia, menyajikan secara khusus dalam sub judul bukunya tentang problema Agama dan Kegagalan, dalam kaitannya terhadap kerangka dasar dakwah, kegagalan dapat dikatakan sebagai sebuah "cobaan bagi orang-orang yang beriman dan taat."(Bustanudin Agus,2005: 264).

Lebih jauh jika kita kembali kepada pola pemikiran bahwah dakwah memiliki potensi kegagalan dalam proses implementasinya di tengah tengah masyarakat, tentunya menjadi penting bagi kita untuk mencari dan meng evaluasi secara menyeluruh pada bagian-bagian mana konsep dakwah yang kita terapkan sebagai indikasi kegagalan, yang membutuhkan pembaharuan dan evaluasi menyeluruh. Bergeser lebih jauh, Studi ilmiah dan beberapa konseptual dakwah dalam potret Malysia, Universiti Malaya menampilkan beberapa bagianbagian penting dalam implementasi dakwah :

Umat Islam kini masih gagal membawa contoh kepada masyarakat,2)Daya jihad dan ketahanan diri yang lemah untuk mencapai matlamat hidup,3)Kesatuan yang lemah, maka sering berpecah-belah atau membiarkan sahaja yang lain,4)Bekerja dalam dakwah dengan kefahaman masing-masing yang dianggap itulah yang betul atau paling kurang yang terbaik,5)Kurang perancangan yang jelas dalam sesuatu tindakan dakwah, apalagi suatu strategi yang sesuai.(Abdul Aziz, 2013:V).

Berangkat dari beberapa hasil analisis dan penelitian yang dilakukan oleh tokoh-tokoh Islam dalam melihat fenomena dakwah di Malaysia dari berbagai aspeknya, tentu menjadi evaluasi dan bahan renungan bagi semua praktisi yang giat dalam berdakwah di 
Indonesia, terlebih posisi Indonesia dengan memiliki keragaman dan kultur budaya yang beragam, tentu menjadi tugas utama bagi kita umat muslim Indonesia untuk benar-benar cermat dalam mengimplementasi dakwah ditengah-tengah sosial masyarakat, sehingga tidak menimbulkan gejolak sosial dan mengotori marwah Islam, dengan karakteristik sebagai Agama Rahmat bagi semesta. Lebih jauh, dapat kita pahami bahwah ilmu pengatahuan, merupakan kerangka dasar yang mesti benar-benar dibangun secara kuat dari berbagai aspeknya, dan sudah semestinya setiap muslim berkeinginan membuka diri secara luas terhadap berbagai pengatahuan, terlebih ilmu yang berkaitan dengan sosial masyarakat. Meminjam pandangan dan pujian penulis biografi Muhammad Iqbal, seorang penyair dan Filosof India, bahwah "tidak ada manusia yang serba bisa, produktif, dan jenius, tanpa siap membuka diri terhadap sesuatu yang kontras sekalipun dengan pemikiran kita". (Rober D.Lee, 2000: 69). Oleh karna itu kami berasumsi bahwah langkah membuka diri terhadap berbagai pengatahuan dapat menjadi nilai lebih bagi para praktisi dakwah, terlebih praktisi dakwah dalam konteks Indonesia.Bergeser lebih jauh, Abu hanafiah memberikan analisis mendalam terhadap Manhaj dakwah Syaikh Sa'id Hawwa, bahwah persesuaian dakwah dengan kondisi kekinian merupakan implementasi dakwah yang sangat efektif :

Pengaplikasian dakwah memerlukan mekanisme yang sesuai selaras dengan tuntutan semasa. Bagi melahirkan da`i dan modal insan yang terbilang selaras dengan tuntutan agama dan cabaran semasa, Syeikh Sa id Hawwa juga telah menghasilkan beberapa karya penulisan beliau yang berkait rapat dengan rangkaian epistemologi dakwah, pembangunan, dan amal Islami sebagai pendedahan teori kepada para da`i. Antara karya-karya hasil penulisan beliau yang berkaitan dengan tema di atas termasuklah Fi Afaq al-Ta'ali, Durus fi al-'Amal alIslami, Min Ajl Khutwah ila Tariq al-Jihad al-Mubarak, dan alMadkhal ila Da'wah al-Ikhwan al-Muslimin. Penghasilan karya-karya terbabit sekaligus telah dijadikan sebahagian silibus dalam manhaj pendidikan rabbani hasil cetusan idea beliau. Syeikh Sa id Hawwa turut menghuraikan konsep kepimpinan Islam (qiyadah) serta kriteria barisan pemimpin dalam menerajui nakhoda gerakan Islam dalam karya beliau, 
Fusul fi al-Imrati wa al-Amir meliputi akhlak pemimpin, perlantikan pemimpin, kewajipan yang harus dipikul oleh saf kepimpinan, dan sebagainya. (Abu Hanafiah,2013: 12).

Lebih lanjut, jika kita menganalisa beberapa kerangka konseptual dari beberapa praktisi AcademikUniversiti Malaya tersebut, memiliki relevansi dengan beberapa hasil penelitian ilmiah dalam tradisi akademik di Indonesiadalam menyingkapi kerangka dakwah sebagai ilmu.Sebut saja seperti Erham Budi Wiranto, dalam artikelnya Dakwah dan Objektifitas Keilmuanyang di publish oleh Jurnal dakwah UIN Sunan Kalijaga, menampilkan salah satu sampel yang sangat penting dalam menempatkan sikaf keterbukaan terhadap pengatahuan secara luas, dalam paper ini Budi menggambarkan bahwah para pendakwah yang memahami sumber-sumber keagamaan dengan melakukan studi terhadap sumber utama ajaran Agama non Islam berpotensi lebih efektif dalam berdakwah kepada non muslim ketimbang para pendakwah yang notabenenya hanya memiliki pengatahuan terhadap Islam belaka.

Juru dakwah yang belajar religious studies umumnya, tidak membangun jarak dengan otoritas dari agama lain, misalnya pemuka agama lain maupun kitab suci agama lain. Seorang da'i yang belajar religious studies merasa nyaman untuk bertemu, bertukar pikiran, dan bekerja sama dengan para pastor, pendeta, rabi, bhikkhu, pandita, haksu, sense, dan para pemuka agama lainnya. Begitu pula dengan kitab suci, para da'i tidak akan alergi untuk membuka dan membaca Injil, Weda, Tripitaka, Baghavad Gita, Tao The Tjing, KojikiNihongi, dan berbagai kitab lainnya. Dengan kemampuan interaksi pada sumber-sumber primer dan sekunder agama lain, maka seorang juru dakwah justru semakin memiliki otoritas untuk menegaskan keuggulan kitab suci Al-qur'an sekaligus mengapresiasi kalimatun sawa atau nilai-nilai luhur yang sama-sama dimiliki oleh Islam dan agama-agama lain.(Budi Wiranto, 2018: 160).

Dari beberapa uraian maupun ulasan sebelumnya, secara sederhana kami memahami bahwah keberhasilan dakwah sangat erat kaitannya dengan personal pendakwah, terutama menyangkut pengatahuan, dan keinginan disertai kesiapan untuk membuka diri secara lebih luas, sehingga tuntutan dan tugas mulia yang kita sebut sebagai dakwah ini, benar-benar dapat di implementasikan dengan baik sesuai dengan tuntunan, maupun kesesuaian dengan tuntutan. 


\section{Sekilas Tentang Perkembangan dan Studi Dakwah di Indonesia}

Secara garis besar perkembangan ilmu dakwah dapat diklasifikasikan kedalam tiga fase perkembangan atau melalui tiga tahap dalam perkembangannya, yaitu "pembentukan ilmu dakwah, pengembangan akademis dan dakwah menjadi salah satu disiplin ilmu.'(Rasyid Ridla, 2017: 75).Menyoroti Tranformasi dakwah yang selama ini dikenal sebagai sebuah profesi untuk menjadi disiplin ilmu, tentu menuai berbagai reaksi dari berbagai kalangan, oleh karena itu Adul Munir berasumsi“"paradigma dakwah sebagai suatu ilmu menanggung konsekuensi dan harus senantiasa siap untuk di uji dengan kebenaran perspektif dari berbagai ilmu lainnya." (Abdul Munir, 1993: 170)Beberapa ulasan dalam tulisan ini, berupaya menyajikan beberapa aspek dan tinjauan Dakwah dalam perkembangannya hingga menjadi disiplin ilmu.

\section{Pembentukan Ilmu Dakwah}

Dalam menyoroti perkembangan ilmu dakwah tercatat dalam sejarah dan pemikiran Islam ditandai dengan "upaya Fakultas Ushuludin Al-Azhar Kairo, pada tahun 1942 dengan membuka jurusan Dakwah.” (Rasyid Ridla, 2017: 75). Senada dengan itu, Harjani Hefni menyatakan bahwah "ilmu dakwah sebagai bagian dari Ilmu Minhaj aqidah dan ushuludin", ditinjau dari usia perkembangannya, ilmu dakwah termasuk suatu ilmu yang cukup muda dibandingkan dengan ilmu-ilmu lainnya yang dapat dikatakan cukup mapan dari berbagai aspeknya.(Harjani : 1). Bergeser lebih jauh jika kita melihat perkembangan Dakwah sebagai ilmu, yang dikembangkan oleh para akademisi di Indonesia, Dakwah sebagai ilmu sudah berusia tidak kurang dari 69 tahun yang tentunya di pelopori oleh fakultas Ushuluddin.

Di Indonesia, pemahasan soal dakwah di dunia akademik sudah dimulai sejak berdirinya PTAIN pada tahun 1950-an. Kemudian dilanjutkan dengan dibukanya jurusan dakwah pada Fakultas Ushuludin tahun 1960.Perkembangan selanjutnya menjadi program studi pada setiap perguruan Tinggi Islam yang ada diseluruh Indonesia. Iain Sunan Kalijaga adalah yang pertama kali membuka jurusan dakwah, yang selanjutnya di ikuti oleh IAIN yang lain. (2017: 76). 
Jika kita menganalisa secara menyeluruh pada pangkalan data Ristek Dikti, kita dapat menemukan angka yang cukup signifikan dalam perkembangan Ilmu dakwah di perguruan tinggi Islam di Indonesia, tercatat lebih dari 250 jurusan Agama Negeri dan 200 program studi dalam modul Statistik, seuah fenomena perkembangan yang cukup tinggi dalam sejarah pendidikan kita. Berbagai problem dan asumsi masyarakat terhadap dakwah hanya sebagai profesi, menjadi hambatan perkembangan Ilmu dakwah, sehingga peran penting para intlektual dalam tradisi akademik sangat menentukan terhadap perkembangan ilmu dakwah kedepan guna menjadikan Dakwah sebagai ilmu yang mapan dan dapat di sejajarkan dengan ilmu-ilmu lain yang sudah cukup mapan dan berbagai aspek keilmuannya.

\section{Dakwah dan Perkembangannya di Lingkungan Akademik}

Sebagai ilmu yang cukup baru dikenal oleh masyarakat, Dakwah yang selama ini dipandang hanya sebagai sebuah profesi yang kemudian berkembang menjadi Ilmu, tentunya membutukan upaya dan pengkajian mendalam oleh berbagai kalangan akademik di Indonesia, sampai saat ini kita dapat melihat berbagai aspek yang cukup mengembirakan sebagai hasil upaya para akademisi dalam mendesaint dakwah sebagai disiplin Ilmu, di tinjau secara akademik aspek dakwah dapat dilihat dari beberapa komponen yaitu "pengembangan tahun 1978, tahun 1982, dan tahun 1986" yang melibatkan seluruh Pendidikan tinggi Islam dalam meng evaluasi pelbagai aspek Dakwah. (Rasyid Ridla, 2017: 80). Dalam perkembangannya Rasyid Ridla menyajikan beberapa komponen yang didesain dalam ilmu dakwah pada fase-fase pengembangannya. Pada kurikulum 1988 pembahasan Ilmu dakwah sudah sudah mendekati sempurna, karna dikupas secara rinci kearah disiplin Ilmu. Yang mencakupu topic-topik antara lain: 1) Definisi ilmu dakwah, 2) Dasar hukum dan tujuan dakwah, 3) Ruang lingkup pembahasan ilmu dakwah, 4) Pertumbuhan dan perkembangan ilmu dakwah, 5) Metodologi Ilmu Dakwah, 6) Hubungan dakwah dengan ilmu lainnya, 7) Komponen dan faktor ilmu Dakwah, 8) Dakwah dalam pelaksanaannya. (Rasyid Ridla, 2017: 81). Hingga masuk pada fasefase akhir, dakwah kembali mengalami pengembangan dan perombakan yang terjadi diberbagai pendidikan tinggi Islam di 
Indonesia, yang bertujuan menyelaraskan antara tuntutan dakwah sebagai profesi, dan pengembangan dakwah sebagai disiplin Ilmu. Sehingga dakwah, benar-benar bisa menjadi suatu disiplin ilmu yang bisa memiliki potensi yang besar, untuk dapat dimanfaatkan oleh masyarakat, menyesuaikan dengan kebutuhan, hingga mempermudah langkah kedepan bagi lulusan dakwah dengan dibekali berbagai skill keilmuan yang didapatkan ketika menempuh pendidikan.

Tabel 1.1 Beberapa Komponen Ilmu Dakwah

\begin{tabular}{|l|l|c|}
\hline No & \multicolumn{1}{|c|}{$\begin{array}{c}\text { Komponen Ilmu } \\
\text { Dakwah }\end{array}$} & $\begin{array}{c}\text { Cakupan } \\
\text { Mengulas pengertian dakwah } \\
\text { seccara Etimologi dan } \\
\text { Termenologi }\end{array}$ \\
\hline 1 & Definisi Dakwah & $\begin{array}{c}\text { Memuat landasan hukum dan } \\
\text { prioritas pengembangan Dakwah }\end{array}$ \\
\hline 2 & Landasan \& Tujuan & $\begin{array}{c}\text { Memuat tentang bagian kajian } \\
\text { dan objek bahasan secara } \\
\text { menyeluruh }\end{array}$ \\
\hline 3 & Ruang Lingkup Ilmu & $\begin{array}{c}\text { Tinjauan Histori, Epistemologi, } \\
\text { dan Pemikiran Islam }\end{array}$ \\
\hline 5 & $\begin{array}{l}\text { Perkembangan Ilmu } \\
\text { Dakwah }\end{array}$ & $\begin{array}{c}\text { Memuat aspek pendekatan dan } \\
\text { kajian dakwah sebagai ilmu }\end{array}$ \\
\hline 6 & $\begin{array}{l}\text { Hubungah } \\
\text { dengan Ilmu Lainnya }\end{array}$ & $\begin{array}{c}\text { Memuat dan identifikasi posisi } \\
\text { Dakwah ditengah Ilmu-Ilmu yang } \\
\text { sudah ada }\end{array}$ \\
\hline 7 & Komponen Ilmu Dakwah & $\begin{array}{c}\text { Memuat beragai aspek dakwah } \\
\text { secara teoritis }\end{array}$ \\
\hline 8 & $\begin{array}{l}\text { Dakwah dan } \\
\text { Pelaksanaannya }\end{array}$ & $\begin{array}{c}\text { Memuat berbagai pendekatan } \\
\text { fenomenalogis dan tinjauan } \\
\text { dakwah secara praktis }\end{array}$ \\
\hline
\end{tabular}

Kompnen Ilmu Dakwah (2017: 81)

\section{Dakwah Sebagai Disiplin Ilmu}

Dalam perjalanan dan perkembangannya, kegigihan para ahlih berhasil menyusun kerangka dasar ilmu dakwah sehingga dakwah di kelompokkan menjadi tiga disiplin utama yaitu "Ilmu Komunikasi penyiaran Islam, pengembangan masyarakat Islam dan Menajemen Dakwah.” (Rasyid Ridla, 2017: 83). Lebih jauh, rasyid Ridla 
meyakini bahwah adanya gejolak dalam perdebatan dalam menyusun kerangka ilmu dakwah disebabkan adanya suatu realitas dakwah yang menempatkan ia kepada salah satu disiplin ilmu yang sudah ada seperti ilmu sosial, ilmu psikolog dan ilmu komunikasi.

Lebih jauh, dalam kajian akademik dan berbagai upaya studi dakwah di Indonesia, kerangka konseptual merupakan acuan utama dalam memahami dakwah sebagai disiplin ilmu, terlebih dalam melihat fenomena sosial yang sempat memanas belakangan ini.Tentunya implementasi dakwah menjadi sorotan penting bagi setiap komunitas baik menyangkut subtansi maupun aplikasi dakwah dalam praktiknya di lapangan. M Rasyid Ridla, dalam karyanya Dakwah: sejarah, Perspektif dan Ruang Lingkup menyusun secara sitematis pola dan pengantar dakwah baik bagi praktisi maupun professional pendakwah. Beberapa kerangka acuan yang di usung oleh M Rasyid Ridla kami rangkum secara sederhana dalam bahasan ini.

Dalam menjelaskan landasan maupun konsep dakwah $\mathrm{M}$ Rasyid mengingatkan bahwah Al-Qur'an sebagai sumber ajaran Islam memberikan penekanan akan pentingnya dakwah dalam Islam, sehingga sudah seyogyanya bagi semua pihak menggunakan berbagai pendekatan yang lebih arif dan betul betul dapat memahami objek dakwah baik menyangkut kultur budaya, adat istiadat, dan kondisi sosial. Sehingga pada akhirnya dakwah dapat berjalan dengan baik, dan masyarakat dapat merasakan dakwah sebagai kontribusi penting dalam beragama, lebih-lebih dalam bernegara.Dalam menjelaskan konsep dakwah M Rasyid Ridla, mengklasifikasikan konsep dakwah menjadi dua again yaitu konsep Al-Qur'an dan konsep Al-Hadits. Pertama Tadzkir, yaitu mengingatkan kepada orang yang lupa supaya kembali kepada jalan yang baik, terdapat dalam Adz.Dzariyat: 55. Kedua Nadzir,yaitu menyampaikan peringatkan dengan menyampaikan kabar-kabar yang menakutkan, Qs. Al-Maidah: 15. Ketiga Basyir, yaitu menyampaikan kabar gembira yang menyenangkan, Qs. Al-Baqarah: 155, Keempat Ishlah mendamaikan perselisihan, Qs. Al-hujurat: 13, Kelima Nashihah, yaitu menyampaikan nasehat kepada seseorang baik diminta maupun tidak, Qs. Al-Ashr: 3. (M Rasyid Ridla, 2017: 10). 


\section{Studi Dakwah Di Malaysia}

Malaysia merupakan suatu Negara yang memiliki populasi muslim mayoritas dengan lebih dari " $61 \%$ mayoritas penduduk menganut Agama Islam" dengan menggunakan bahasa melayu sebagai bahasa resmi, Lebih jauh dalam menggambarkan etnoLinguistik, Ajid Tohir dengan mengutip pandangan seorang sarjana Ingris, J. Crawfurd bahwah ditinjau dari segi bahasa "seluruh rumpun bahasa melayu adalah berasal dari sumatera," . (Ajid Thohir, 2009: 68)terlepas dari berbagai pandangan yang berbeda dalam tinjauan aspek-aspek lainnya. Jika kita menyoroti upaya besar yang dilakukan oleh para akademisi dalam lingkungkan Universiti Malaysia, nampakna Dakwah menjadi suatu priroritas penting bagi para akedemisi Universiti Malaya, hal ini dapat kita lihat dari geliat para akademisi dalam melakukan studi-studi terhadap dakwah baik secara konseptual maupun dalam melakukan studi lapangan, guna menemukan pelagai pola dalam mendesain dakwah seagai disiplin ilmu dan aktivitas praktis dalam kehidupan. Lebih Lanjut, jika kita lihat dari sudut pandang keagamaan,Ismail Suardi Weke dalam artikel ilmiahnya yang di Publish oleh jurnal Millah, meyatakan bahwah Islam menjadi suatu Agama resmi bagi Malaysia.

Malaysia merupakan salah satu negara yang multietnik tetapi dengan tegas menyatakan bahwa Islam menjadi dasar penyelenggaraan tata pem erintahan.Tidak hanya dalam pem erintahan tetapi juga dalam perekonian secara umum.Di awal tahun 1980 mulai memperkenalkan sistem perbankan syariah.Disamping tetap memberikan keluasan bagi perbankan dengan system konvensional.Bahkan dengan tegas kemudian menyelenggarakan dua sistem perbankan dalam satu negara.Dalam penelitian Benson membuktikan bahwa sistem perbankan syariah dapat bersaing dengan perbankan konvensional. Dalam beberapa hal justru perbankan dengan prinsip-prinsip syariah lebih dapat memenuhi tuntutan pasar serta memperoleh profit yang tinggi.(Ismail, 2013: 303)

Sistem kenegaraan Malaysia yang didominasi penduduk mayoritas Muslim serta ditopang oleh system pemerintahan yang mensuplay berbagai kegitan maupun agaenda keagamaan,serta politik kenegaraannya, tentu tidak dapat kita samakan dengan kondisi 
georafis keagamaan di Indonesia, karna Indonesia sejak pertama berdirinya mengproklamirkan diri sebagai Negara yang berdasarkan Pancasila, dimana dapat kita pahami politisasi dalam aspek kepentingan Agama tertentu tidak lebih leluasa dibandingkan dengan Malaysia. Sungguhpun demikian Adian Husaini dalam karyanya kerukunan beragama meyakini sungguhpun Indonesia tidak mengakui agama tertentu sebagai agama resmi Negara, tetapi Indonesia diyakini sebagai Negara yang Netral Agama sehingga seyogyanya "Negara tidak boleh terlibat dalam satu tafsir keagamaan tertentu."(Adian Husaini, 2015:34).Dalam tulisan ini peneliti berupaya mengangkat beberapa studi dakwah yang dilakukan oleh para akademisi Universiti Malaya sebagai tradisi akademik di Malaysia.

\section{Studi Dakwah Ahmad Fakhruddin dan Roslan}

Dalam penelitiannya, Ahmad Fakhruddin dan Roslan menekankan penelitiannya pada permaslahan geliat politik dan dakwah.Pada ulasan awal nampaknya Fakhruddin memahami politik sebagai suatu tatanan pokok yang mengatur menajemen dan administrasi sesuai dengan kerangka acuan ajaran Islam baik dalam mengatur tata kelola kehidupan secara umum maupun perihak kewarganegaraan.

Oleh itu, pengertian politik Islam dapat disimpulkan dengan pengurusan dan pentadbiran yang bijak berasaskan kriteriakriteria yang telah ditetapkan dalam Islam terhadap sebarang urusan kehidupan dan kenegaraan.Di dalam politik Islam, agama menjadi tunjang kepada sistem politik sesebuah Negara.(2013: 169).

Jika kita analisa dan melihat beberapadaftar bacaan yang diambil guna memperkuat pemikirannya, Fakhruddin dan Roslanmenyandarkan pandangannya terhadap Muhammad Dhiya AlDin Al-Rayes, Nadariyat al-Siasat al-Islamiyah, serta menandaskan pandangannya mengenai dakwah terhadap pemikiran Dr. Yusof AlQardawi, dalam karyanya Thaqafah Al-Da'iyah.Berangkat dari beberapa pemikiran diatas secara spesifik kedua akademisi Universiti Malaya ini beranggapan bahwah.

Dakwah dan politik merupakan dua elemen yang sangat berkait rapat melalui peranannya terhadap pembangunan dan pengurusan kehidupan manusia. Ini kerana, peranan politik dan dakwah adalah 
saling melengkapi antara satu sama lain. Selain itu, dakwah dan politik merupakan usaha dalam mengurus kehidupan manusia meliputi semua aspek berlandaskan kepada batas-batas syariat Islam, menuju kepada pencapaian fitrah manusia iaitu beriman kepada Allah serta mencapai matlamat utama dakwah Islamiah iaitu untuk membina Negara Islam sepertimana yang telah ditunjukkan oleh Rasulullah S.A.W. Dengan kata lain, politik merupakan salah satu juzuk daripada mauduk pendakwahan yang bermatlamatkan kebahagiaan di dunia dan di akhirat. (2013: 170).

Dari beberapa ulasannya dapat kita pahami, bahwah kedua Akdemisi ini berkeyakinan kalau politik dan dakwah dalam tinjauan studi Islam, adalah dua elemen penting, yang memiliki kaitan erat dalam perkembangan agama Islam.Beberapa tela'ah dan tinjauan sejarah yang dikemukakan oleh kedua akademisi ini, menunjukkan bahwah keduanya memiliki pemikiran bahwah politik merupakan suatu arena efektif dalam melakukan atau menerapkan dakwah.Politik bagi kedua akademisi ini bukanlah suatu perkara yang baru dalam Islam sebagai suatu Agama.

Politik dalam Islam sangat penting dalam usaha untuk mengurus, mentadbir dan memimpin manusia untuk menuju kepada kehidupan yang diredai Allah S.W.T. Dalam masa yang sama, politik Islam juga berperanan sebagai wasilah dakwah. Hakikat ini bukanlah sebagai suatu perkara yang baru bagi umat Islam, bahkan pendapat yang mengatakan dakwah dan politik sebagai dua perkara yang berasingan hanyalah akan merugikan umat Islam itu sendiri. Malah pendapat tersebut juga dianggap sebagai menafikan pembabitan Rasulullah S.A.W dalam berpolitik sebagai ketua pemerintah kerajaan Islam di Madinah. Pada masa yang sama juga kebangkitan para ulama dan tokoh Islam dalam melontarkan hujah dan memberi amaran yang keras kepada golongan yang berfikiran sekularisme dan liberalisme, sekaligus telah menafikan dan menolak pendapat yang memisahkan agama dan politik amnya serta dakwah dan politik khususnya .(2013: 190).

\section{Studi Dakwah Juwairiah\& Prof. Dr Ab Aziz Mohd Zin}

Dalam studi ini, juwairiah berupaya memaparkan pola-pola dakwah yang efektik dalam mengimlementasikan dakwah pada golongan tuna Netra. Adapun wilayah penelitian yang dilakukan 
juwairiah berlokasi di Terenganu Malaysia.Lebih jauh jikDari beberapa rangkaian ulasan dan penjelasannya, peneliti memberikan beberapa catatan dalam program dakwah kepada kelompok orangorang tuli di Terenganu Malaysia, yang diklasifikasikan menjadi tiga program secara umum, yaitu "program dakwah bulanan, program dakwah mingguan, dan harian.”(Juwairiah, 2013: 209). Dari beberapa ulasan dan analisa peneliti menemukan bahwah pola dakwah di identifikasi dalam penelitian Juwairiah adalah menerapkan implementasi bahasa Isarat, dengan metode dialog.

\section{Studi Dakwah Nik Suhaida}

Dalam penelitian yang dilakukan Nik Suhaida ini, dapat dikatakan sebuah studi lapangan dengan menggunakan studi kualitatif, adapun kawasan wilayah penelitian berlokasi di klantan Malysia. Bergeser kepada analisis dan temuannya, dapat di ketahui bahwah metode dan indikasi keberhasilan penaggulangan miras di kawasan Klantan menggunakan "metode penerapan Hukum Islam" dalam suatu peraturan pemerintahan, sehingga kebijakan pemerintah, sebagai medium utama dalam memberantas miras, dengan pertimbngan tidak melarang bagi non muslim mengkonsumsi dan menjual miras, meskipun ada ketentuan ketentuan yang diberlakukan, seperti tidak menjual secara terbuka. (Nik Suhaida, 2013: 256). Lebih lanjut, Suhaida mengatakan :

Metode dakwah kepada orang bukan Islam yang digunakan dalam pelaksanaan kawalan penjualan arak di Negeri Kelantan ini adalah menggunakan medium undang-undang. Melalui medium ini prinsip dakwah yang dikenalpasti adalah mencegah kemungkaran melalui gaya persembahan dakwah yang melibatkan ketegasan tetapi mengekalkan nilai ajaran Islam yang terkandung di dalam prinsip undang-undang Islam dan juga seni dakwah iaitu menghormati hak sesama manusia walaupun berbeza agama dan saling menghormati agama masing-masing.(Nik Suhaida,2013: 257).

Lebih lanjut, jika kita melihat dalam konteks Indonesia, tentunya pada kawasan dan wilayah pada umumnya di Indonesia, lebih sulit untuk menerapkan hukum Agama tertentu yang di adopsi kedalam peraturan Daerah, karna Indonesia bukan merupakan Negara agama atau berdasarkan Agama tertentu, sehingga dalam bahasa lain potensi kontras sosial dalam mempermasalahkan hal ini pasti akan 
bereaksi, sehingga pada akhirnya akan menimbulkan geliat-geliat sosial yang bisa mempengarui hubungan antar umat beragam. Kalaupun langkah ini diambil oleh pemerintah daerah di berbagai kawasan indonesia, kami berasumsi selama pemerintah mengeluarkan keijakan tanpa mengangkat Isu-Isu Agama tertentu, kebijakan ini dapat diterima, tanpa penentangan berarti.

\section{Studi Dakwah di Brunei Darussalam}

Dalam tulisannya The Bureaucratisation of Islam in Southeast yang di publikasi oleh Journal of Current Southeast Asian Affairs, Muler Dominik berupaya menampilkan berbagai hasil studinya dalam menyoroti perkembangan dan proses penyebaran Islam dengan menyoroti secara spesifik fenomena Islam dalam proses implementasi dakwah. Pada ulasan awal, Muler dan Stener menggaris bawahi bahwah Islam bukan seperti katolik yang memiliki pemimpin pusat, ketika menanggapi beberapa gejolak politik Islam dari beberapa tinjauan sejarah perkembangan Islam, meskipun pada sisi lain bagi Muler tidak dapat dinampikan bahwah adanya beberapa fase yang menunggangi dakwah dalam menggapai kepentingan kekuasaan.

Islam is not a church institution, it lacks the centralised leadership and institutions associated with Christianity. This common wisdom is first semester knowledge for students of Islamic Studies, and a frequently invoked formula among experts responding to what they consider inadequate representations of Islam and misplaced expectations towards Muslims. Its invocation counters ways of looking at Islam through the lens of Christianity and the epistemic modes of European secularity, resulting in Eurocentric equations that overlook fundamental differences between two discursive traditions that are, in many ways, distinct (Asad 1986: 5).1 Taking the critique of false comparison and inappropriate terminology one step further, the very category of religion has been problematised vis-à-vis its (non-)applicability to nonWestern settings (Asad 19932 ), albeit with little if any impact in wider public debates. But what happens when state actors operating in the name of Islam, or Muslim communities themselves, seek to adapt Islamic discourse to bureaucratic settings of the modern nation state that many observers have 
described as fundamentally alien to "authentic" Islam. (Muler Dominik M, 2018: 3).

Sejalan dengan itu, jika kita melihat beberapa tulisan ulamaulama di Indonesia seperti Buya Hamka dalam karyanya keadailan sosial dalam Islam telah menggaris bawahi bahwah "politisasi kepentingan kelompok dalam menunggangi gerakan dakwah Islam bukan merupakan, subtansi yang menunjukan eksistensi Islam sebagai Agama politik." Bagi Hamka, beberapa fenomena yang terjadi dalam perkembangan dan fase gejolak politik yang terjadi diberbagai Negara islam di dunia tidak dapat dikaitkan dengan Islam, meskipun notabenenya menggunakan simbol-simol Islam yang digunakan diberbagai orasi politik. (Buya Hamka, 2015: 159). Islam dalam tujuan dan misi dakwah hendaknya menyelaraskan terhadap geo politik dalam memperjuangkan nilai-nilai islam, sehingga tidak terjadinya chaos antara Islam sebagai Agama dan peraturan pemerintah dalam suatu Negara tertentu, sebut saja seperti Hasan Albanna yang berkeyakinan bahwah "apapun bentuk negaranya, baik republik maupun kerajaan, yang utama adalah penerapan hukum Islam memiliki ruang dalam suatu Negara."(Yuni Fadilah, 2017: 85).Bergeser lebih jauh, jika melihat beberapa temuan dalam studi yang dilakukan Muler dan Stainer, keduanya berasumsi bahwah citacita dalam mendirikan suatu Negara yang berdasarkan hukum islam sudah menjadi perbincangan umum bagi berbagai kalangan akademik, terlebih menjadi suatu khayalan bagi kebanyakan kalangan Islam diberbagai Negara karna sangat sulit menyelaraskan pondasipondasi Negara yang sudah mengakar dengan menawarkan Islam sebagai sebuah solusi bagi suatu system pemerintahan dan kenegaraan.

Of course, the state is not a monolithic entity, even though it is often portrayed as such, and indeed often portrays itself as such. Although "calls for ethnographic exploration of the everyday workings of the state have grown louder" (Hoag 2011: 81) elsewhere, such calls have not yet been taken up more widely in the study of Southeast Asian state-Islam relations - which may contribute to essentialising narratives about the state too often remaining unquestioned, even in academic accounts. Any "state" provides "a complex social arena" in which bureaucrats are key participants (Bernstein and Mertz 2011: 6), who are actively engaging in complex 
social relations among themselves and with their "nonbureaucratic" environment. Even the assumedly "strongest" state is, in such an understanding, a fragile and fragmented entity that must be constantly reproduced, irrespective of whether we see its existence as a fixed given in legal terms, or anthropologically merely as a fiction or "intellectual fetish" that has "never existed at all"14 see Graeber and Sahlins 2017: 21; but see Thelen, Vetters, and von Benda-Beckmann 2014 for an anthropologically more nuanced approach reconciling the study of representations of the state with actual state practices and interactions. (Muler Dominik M, 2018: 10).

Pada ulasan akhirnya, Muler menyimpulkan bahwah birokrasi Islam di brunei Darusalam memiliki problem dan potensi yang dapat menyebabkan ketimpangan sosial dalam menjalankan roda pemerintahan oleh karena itu, dalam upaya penyelidikan dan studi ini muler berkeyakinan bahwah langkah studi yang dilakukan dapat memberikan kontriusi dalam mengevaluasi secara menyeluruh birokrasi di Brunei, sehingga jalannya roda pemerintahan dapat benar-benar memiliki kesesuaian dengan ideology Negara. 
18 Eko Nopriyansa, Dakwah Dalam Tradisi Akademik,....

Abdul Munir Mulkhan. 1993 Paradigma Intlektual Muslim, Yogyakarta: SIPRESS.

Abuddin Nata, 2006. Metodologi Studi Islam, Jakarta: Rajawali Press.

Adian Husaini, 2015.Kerukunan Beragama dan Kontroversi Penggunaan Kata Allah dalam Agama Kristen, Jakarta: Gema Insani.

Bustanuddin Agus, 2005. Agama dalam Kehidupan Manusia, Jakarta: PT. Raja Grafindo Persada.

Didin Hafiduddin. 2003. Islam Aplikatif, Jakarta: Gema Insani.

David Litle dkk. 1997. Kebebasan Agama dan Hak-hak Azazi Manusia, Yogyakarta: Pustaka Pelajar.

Hamka. 2015. Keadilan Sosial dalam Islam, Jakarta: Gema Insani.

Harun Nasution. 1975. Pembaharuan Islam, Jakarta: PPBB.

Jhon.L Esposito, 2005.Jawaban atas Gejolak Masyarakat PostModern, Islam Aktual, Depok: Inisiasi Press.

Karel. A. Steenrink. 1984. Beberapa Aspek Tentang Islam di Indonesia Abad ke-19, Jakarta: Penerbit ulan Bintang

Kemendikbud. 2017. Ilmu Pengatahuan Sosial, Jakarta: Balitbang.

Moeslim Abdurrahman. 2003. Islam Sebagai Kritik Sosial, Jakarta: Penerbit Erlangga.

Muhammad Imarah, 1999. Islam dan Pluralitas Perbedaan dan Kemajemukan dalam Bingkai Persatuan, Jakarta: Gema Insani.

Robert D. Lee, 2000. Mencari Islam Autentik, Bandung: Penerbit Mizan. 
Rohimin dkk. 2009. Harmonisasi Agama dan Budaya di Indonesia, Jakarta: Balitbang.

Syarifuddin, 2005. Manajemen Lembaga Pendidikan Islam, Jakarta: PT. Ciputat Press.

Syaikh Syaifurrahman, 1997. Sirah Nabawiyah, Jakarta: Pustaka AlKautsar.

Yuni Fadilah, R. (2017). Pemikiran Politik Dan Dakwah Hasan ABanna. Journal Filsafat Agama dan Pemikiran Islam, Vol. 02 .

Ahmad Fakhruddin. (2013). Konsep Dakwah Melalui Politik Dalam Islam.Universiti Malaya.

Juwairiah.(2013). Penerimaan Program Dakwah Dalam Kalangan Orang Pekak Di Terenganu.Universiti Malaya.

Nik Suhaida. (2013). Isu Pelaksanaan Kawalan Penjualan Arak di Negeri Klantan.Universiti Malaya. 